\title{
Key Points Concerning Amyloid Infectivity and Prion-Like Neuronal Invasion
}

\author{
Alba Espargaró, Maria Antònia Busquets, Joan Estelrich and Raimon Sabate* \\ Faculty of Pharmacy, Laboratory of Conformational Diseases, Department of Physical Chemistry, Institute of Nanoscience \\ and Nanotechnology, University of Barcelona, Barcelona, Spain
}

Amyloid aggregation has been related to an increasing number of human illnesses, from Alzheimer's and Parkinson's diseases (AD/PD) to Creutzfeldt-Jakob disease. Commonly, only prions have been considered as infectious agents with a high capacity of propagation. However, recent publications have shown that many amyloid proteins, including amyloid $\beta$-peptide, $\alpha$-synuclein $(\alpha$-syn) and tau protein, also propagate in a "prion-like" manner. Meanwhile, no link between propagation of pathological proteins and neurotoxicity has been demonstrated. The extremely low infectivity under natural conditions of most non-prion amyloids is far below the capacity to spread exhibited by prions. Nonetheless, it is important to elucidate the key factors that cause nonprion amyloids to become infectious agents. In recent years, important advances in our understanding of the amyloid processes of amyloid-like proteins and unrelated prions (i.e., yeast and fungal prions) have yielded essential information that can shed light on the prion phenomenon in mammals and humans. As shown in this review, recent evidence

\section{OPEN ACCESS}

Edited by:

Jean-Marc Taymans,

UMR-S 1172, Jean-Pierre Aubert

Research Center, France

Reviewed by:

Nicolas Sergeant,

UMR-S 1172, Jean-Pierre Aubert

Research Center, France Marc Blondel,

Inserm UMR 1078, France

*Correspondence: Raimon Sabate rsabate@ub.edu

Received: 30 November 2015 Accepted: 06 April 2016 Published: 22 April 2016

Citation:

Espargaró A, Busquets MA, Estelrich $J$ and Sabate $R$ (2016) Key Points Concerning Amyloid Infectivity and

Prion-Like Neuronal Invasion.

Front. Mol. Neurosci. 9:29.

doi: 10.3389/fnmol.2016.00029 suggests that there are key factors that could dramatically modulate the prion capacity of proteins in the amyloid conformation. The concentration of nuclei, the presence of oligomers, and the toxicity, resistance and localization of these aggregates could all be key factors affecting their spread. In short, those factors that favor the high concentration of extracellular nuclei or oligomers, characterized by small size, with a low toxicity could dramatically increase prion propensity; whereas low concentrations of highly toxic intracellular amyloids, with a large size, would effectively prevent infectivity.

Keywords: Alzheimer's disease, amyloid, amyloid cytotoxicity, amyloid transmission, Creutzfeldt-Jakob disease, prion, transmissible spongiform encephalopathy

\section{INTRODUCTION}

Many neurodegenerative diseases are characterized by the aggregation of misfolded proteins in the brain, the so-called amyloids. Among these disorders are the prion diseases (Creutzfeld-Jakob disease in humans, bovine spongiform encephalopathy in cattle or scrapie in sheep) and non-prion diseases (Alzheimer's disease (AD), Parkinson's disease (PD) or tauopathies). The presence of amyloids in neurodegenerative diseases appears to be a truly generic phenomenon. As a differential property, prion diseases are assumed to be transmissible whereas non-prion diseases are non-transmissible.

In prion diseases, through a polymerization process, the misfolded proteins (the prions) become a self-perpetuating infectious agent. In this way, they can become neurotoxic 
elements in mammals or protein-based genetic elements in fungi (Chien et al., 2004; Aguzzi and Calella, 2009). In mammals, the central event in prion pathogenesis is the conformational conversion of the normal host prion protein $\left(\mathrm{PrP}^{\mathrm{C}}\right)$ into an abnormal protease-resistant form $\left(\mathrm{PrP}^{\mathrm{Sc}}\right)$ associated with disease. $\mathrm{PrP}^{\mathrm{Sc}}$ propagates by imposing its abnormal conformation on other $\operatorname{PrP}^{\mathrm{C}}$ molecules. But this does not explain how infectious prions proceed to induce the spongy brain lesions of transmissible spongiform encephalopathies and, eventually, extensive neuronal death (Aguzzi, 2005; Chesebro et al., 2005). Hence, although the presence of $\operatorname{PrP}^{\mathrm{Sc}}$ has generally been assumed to be constitutional of neurotoxicity, at the present, $\mathrm{PrP}^{\mathrm{Sc}}$ itself is considered innocuous. In conclusion, the dissociation of the toxic species (what actually kills neurons) and infectious agent (the propagating PrP) has been well established (Hill and Collinge, 2003a,b; Mallucci et al., 2003; Sandberg et al., 2011). Meanwhile, most prion infectious agents are relatively species specific, but cross-species transmissions have occurred in nature and in laboratory experiments (Race et al., 2015).

In non-prion diseases, a host-derived protein is misfolded and persists in an aggregated form that may damage nearby cells $[\beta$-amyloid $(\mathrm{A} \beta)$ in $\mathrm{AD}, \alpha$-synuclein $(\alpha$-syn) in $\mathrm{PD}$, and tauprotein $(\tau)$ in tauopathies and AD (Costanzo and Zurzolo, 2013; Goedert, 2015)]. Although prions and amyloids related to non-prion diseases share structural properties and their conformation, only a small handful of non-prion amyloids display the main prion behavior, i.e., the capacity to spread the self-propagating misfolded proteins from neuron to neuron throughout the brain. In recent years, evidence for prion-like mechanisms in neurodegenerative diseases has come to light. Thus, proteins such as $\tau$ (Polymenidou and Cleveland, 2012; Walker et al., 2013; Goedert et al., 2014; Holmes and Diamond, 2014; Hyman, 2014; Clavaguera et al., 2015; Polanco and Götz, 2015), $\alpha$-syn (Hansen et al., 2011; Freundt et al., 2012; Polymenidou and Cleveland, 2012; Spillantini and Goedert, 2013; Goedert et al., 2014; Reyes et al., 2014; Herva and Spillantini, 2015), A $\beta$ (Bahr et al., 1998; Kane et al., 2000; Meyer-Luehmann et al.,
2006; Eisele et al., 2010; Münch et al., 2011; Nath et al., 2012; Stöhr et al., 2012; Walker et al., 2013), huntingtin (Ren et al., 2009; Trevino et al., 2012; Banez-Coronel et al., 2015), SOD1 (Münch et al., 2011; Polymenidou and Cleveland, 2011) or TDP-43 (Furukawa et al., 2011) have been shown to undergo seeding aggregation in cell cultures, and some of them even exhibit trans-cellular propagation and the induced spread of pathology in vivo (Goedert et al., 2010; Kaufman and Diamond, 2013). That the conformational changes undergone by $\tau, A \beta$, and $\alpha$-syn could spread between cells was first established in cell models (Petkova et al., 2005; Desplats et al., 2009; Frost et al., 2009). Like classical prions, these proteins form distinct conformers in vivo, and $\mathrm{A} \beta$, mutant $\tau$, and mutant $\alpha$-syn can cause the spread of regional pathology and disease progression in mouse models (Aguzzi and Rajendran, 2009; Clavaguera et al., 2009; Jucker and Walker, 2011; Luk et al., 2012; Mougenot et al., 2012; Stöhr et al., 2012). Moreover, the propagation and misfolding of wild type $\alpha$-syn have also been reported (Luk et al., 2012; Masuda-Suzukake et al., 2013); although it has never been shown to invade neurons. Neuronal invasion entails dissemination through the peripheral (spleen) and central nervous system (CNS) via distal neuronal spreading, as well as individual-to-individual infection under natural conditions. Thus, the capacity of non-prion amyloids to spread is limited to neuron-to-neuron transmission (Desplats et al., 2009; Freundt et al., 2012; Soto, 2012; Reyes et al., 2014). As in prions, the spread of misfolded protein in non-prion amyloids is not evidence of neurodegeneration (Halliday et al., 2014). That is, misfolded proteins in non-prion amyloids can propagate in a "prion-like" manner, but that spreading is, at least partly, separate from neurotoxicity.

Recent advances in the field of conformational diseases, and especially in our understanding of unrelated $\operatorname{PrP}$ prions (i.e., yeast and fungal prions), have shed some light on the key factors that determine the capacity of any amyloid to spread. We now have some indication of which factors limit or favor neuron-toneuron transmission and distal neuronal spreading (Figure 1). In mammals and humans, the prion-like capacity to spread

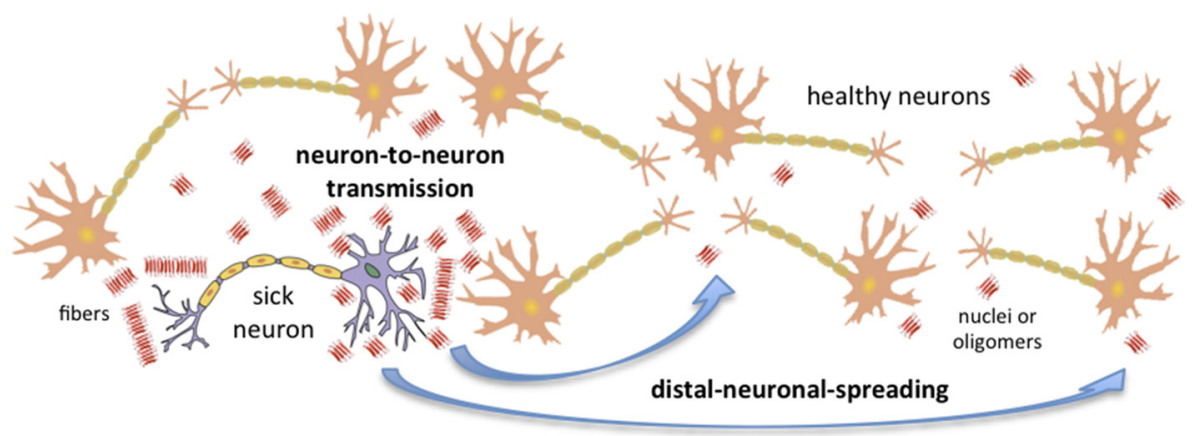

FIGURE 1 | Amyloid transmission mechanisms. Amyloid aggregates could be transmitted from a sick neuron to healthy neurons via two main mechanisms: neuron-to-neuron transmission and distal neuronal spreading. The concentration of nuclei, the presence of oligomers, and the toxicity, resistance and localization of these aggregates are key factors affecting putative neuronal invasion. Note that in order to simplify the figure, only neurons have been considered; nonetheless, it is important to take into account that astrocytes and other cells can also sporadically generate aggregates. 
within an individual seems to be intimately linked to neuronal invasion and ultimately to the individual-to-individual infective capacity.

This review covers the prion-like mechanisms of propagation involved in the spreading of the amyloid conformation. Two potential mechanisms for spread within an individual infected organism (intra-individual spreading) are proposed: (1) neuron-to-neuron transmission, referring to the infection of healthy neighboring neurons directly connected to the infected one; and (2) distal neuronal spreading, entailing the infection of healthy neurons located far from the infected one. Moreover, this review attempts to elucidate, in a simplified form, the key factors that favor or impede neuron-to-neuron transmission and distal neuronal spreading, and thus the neuronal invasion capacity and individual-toindividual infectivity of non-prion amyloids. However, we are aware that other potential mechanisms, involving cell types other than neurons, may also be involved in amyloids spreading. Thus, direct crossing of the blood barrier (Banks et al., 2009), dissemination via astrocytes and fibroblasts (Hollister et al., 2015), infection by inducing microglia recruitment (Baker et al., 2002; Marella and Chabry, 2004; Pearce et al., 2015; Tu et al., 2015) or spreading via immune system cells (Isaacs et al., 2006; Bradford and Mabbott, 2012) represent other potential spreading mechanisms.

\section{NUMBER OF AMASSED NUCLEI}

Amyloid fibrillogenesis is a nucleation-dependent process which depends on protein concentration and can be promoted or triggered by homologous preformed amyloids that act as templates in a mechanism known as seeding (Jarrett and Lansbury, 1993; Chiti and Dobson, 2006). The simplified nucleation-elongation model is divided into three phases: (1) the lag phase, when the soluble and monomeric species cluster to form nuclei; (2) the elongation phase, when monomeric species are exponentially added to previously formed nuclei, entailing the formation of transient species such as protofilaments and protofibrils; and (3) the maturation phase, when the transient species as well as oligomers are grouped together, leading to fibril maturation (Jarrett and Lansbury, 1993). However, in a more realistic scenario, amyloid aggregation has to be considered as an inter-conversional multi-step equilibrium of numerous conformational states, which involves a complex network of equilibriums, wherein secondary nucleation and fragmentation events are also possible (Chiti and Dobson, 2006; Knowles et al., 2009; Cohen et al., 2013; Meisl et al., 2014; Sabate, 2014). In vivo, seeds can trigger amyloid aggregation, promoting the rapid development of symptoms and increasing the infective capacity of amyloid-prone proteins (Aguzzi and Calella, 2009; Stöhr et al., 2012). Thus, the seeding capacity (which is an intrinsic property shared by all amyloids) of yeast and fungal prions has been shown in vivo to be intimately related to the number of nuclei of aggregation per cell as well as the number of amassed nuclei introduced into the cell, which finally determines the probability of transmission of the prion (Maddelein et al., 2002; Tanaka et al., 2006). No relationship has been demonstrated between seeding capacity and the number of nuclei introduced into the cell in the case of mammal prions. However, as seeding is a feature shared by all amyloids, it would seem logical to extrapolate it to the PrP case. Moreover and very interestingly, the possibility of a direct relationship between the concentration of nuclei and the amount of oligomeric material, via "nucleation growth", has been proposed (Lomakin et al., 1996, 1997; Ferrone, 1999; Serio et al., 2000; Morris et al., 2008; Bemporad and Chiti, 2012). This suggests that the seeding capacity would be dependent on the concentration of oligomers (Sakono and Zako, 2010).

In amyloid aggregation, the final concentration of each amyloid species is highly dependent on both intrinsic and extrinsic factors. Consequently, modification of the factors involved in aggregation changes the nucleation and elongation rates, as well as secondary nucleation or fibril fragmentation. Moreover, such changes would imply subtle alterations in the delicate network of equilibriums. It has been shown in fungal prions that the fragmentation of the chaperone Hsp104 increases the number of nuclei per cell; such an increment is essential for prion transmission (Uptain and Lindquist, 2002; Malato et al., 2007). In short, whereas the amino acid sequence of any amyloid-prone protein can determine the conformation and concentration of amyloid species in the network, changes in the cellular conditions (for instance, as a consequence of stress) could alter the inter-equilibrium among amyloid states, resulting in changes in the concentration of nuclei. It should further be taken into account that specific mutations in the primary protein sequence could alter the aggregation capacity of amyloidprone proteins, entailing changes in the ratios between aggregate states, which could drastically modify infective capacity (Chiti and Dobson, 2006; Aguzzi and Calella, 2009). As mentioned above, seeding capacity is directly related to the number of seeds (also termed "events" or "propagons" in yeast and fungal prions) per cell. Furthermore, since seeding is essential for amyloid transformation, the number of seeds per cell could become a crucial factor in the amyloid self-assembly process and in their later propagation. Thus, an increment in the number of amyloid-like aggregates must favor neuron-to-neuron transmission.

\section{AGGREGATE SIZE AND SPREADING CAPACITY}

It is widely accepted that both intrinsic structural characteristics and the size of the species usually formed at the early stages of amyloid aggregation, i.e., oligomers, protofibrils, protofilaments and nuclei (amyloid-like species), can be factors that determine the capacity to spread. Moreover, it has been stated that small amyloid-like species spread the most (Chiti and Dobson, 2006; Aguzzi and Calella, 2009; Nath et al., 2012; Figure 1). If we consider a fixed mass of protein, the size of the aggregates is inversely proportional to the number of seeds per cell, since more aggregates of discrete size would have to be formed to transform soluble protein in its native state into amyloid. Because small aggregates are the most dispersible amyloid-like species, an increased number of these favors both neuron-to- 
neuron transmission and distal neuronal spreading. For instance, $\mathrm{PrP}^{\mathrm{Sc}}$ oligomers, composed of 14-28 monomers, have been shown to be the most infectious PrP particles (Silveira et al., 2005).

\section{TOXICITY OF AMYLOID AGGREGATES}

The in vivo cytotoxicity derived from amyloid aggregation is a consequence of an extremely complex and poorly understood combination of interrelated processes. Among other effects, it eventually entails the formation of pores, homeostatic dysfunction and membrane disruption; which seem to be effects induced by many amyloids (Lashuel et al., 2002; Chiti and Dobson, 2006; Lashuel and Lansbury, 2006). In addition, increasing evidence suggests that cell membranes are potential targets of amyloid aggregates and where much of the molecular damage they cause occurs (Walker et al., 2006). Interactions of amyloid aggregates with phospholipid membranes resulting in lipid peroxidation as well as intracellular aggregation leading to the impairment of cellular functions are believed to be potential causes of later cell death (Walker et al., 2006). Crucially, evidence increasingly indicates that the inherent cytotoxicity of amyloids depends of the amyloid state (Lashuel et al., 2002; Chiti and Dobson, 2006; Lashuel and Lansbury, 2006). Thus, oligomers are usually proposed as one of the most toxic species (Ono et al., 2009; Bemporad and Chiti, 2012). It has been suggested that small amyloid-like aggregates, ranging from 5 to 30 monomers, and to a lesser extent mature fibers could principally be responsible for amyloid toxicity and prion infectivity (Prangkio et al., 2012). The debate concerning the relationship between infectivity and neuronal degeneration is far from resolved; but recent evidence from fungal prions shows that the presence of extremely toxic oligomeric species fully prevents prion propagation (Greenwald et al., 2010; Mathur et al., 2012; Seuring et al., 2012). In summary, for aggregates of the same size, higher toxicity seems to be associated with lower infectivity; while less toxic aggregates would be the most infectious (Sabate, 2014). For instance, it could be speculated that in vivo $\mathrm{PrP}^{\mathrm{Sc}}$ aggregates, which are highly infectious, possess low toxicity and that they might not even be toxic particles per se (Silveira et al., 2005; Chiti and Dobson, 2006; Aguzzi and Calella, 2009). In contrast, in vitro $\mathrm{PrP}^{\mathrm{Sc}}$ oligomers, sometimes not considered to be bona fide authentic $\mathrm{PrP}^{\mathrm{Sc}}$, display extreme toxicity and lack infectivity (Simoneau et al., 2007). In the same way, $A \beta$ aggregates, widely accepted as displaying high toxicity, have largely been considered as non-infectious (Canevari et al., 2004; Chiti and Dobson, 2006; Aguzzi and Calella, 2009). Although certain infectivity under forced conditions in primates and transgenic mice (e.g., by intracerebral inoculation) has been observed in recent years (Walker et al., 2006), infection under natural conditions has never been demonstrated.

Interestingly, toxicity could exert a dual effect on the infective capacity of amyloids. Intracellular amyloids, which have to diffuse from the neuron to the extracellular matrix, require both passive and active mechanisms (Visanji et al., 2013). On the one hand, neuron death, entailing a lack of active mechanisms for amyloid diffusion, could act as a limiting factor in amyloid distribution. Nevertheless, it is important to take into account that, in certain cases, toxicity could also provoke membrane disruption thereby favoring the opposite effect: the extracellular release of aggregation nuclei. Thus, toxic aggregates may kill cells and thereby be freely released into the medium, increasing their chances of spreading. On the other hand, neuron apoptosis and death entails the inhibition of cellular protein production and hence a reduction in the putative amyloid fibrillogenesis, affecting both intracellular and extracellular amyloids. Consequently, high amyloid toxicity involves accelerated neuron death and consequently a premature end to the amyloid process. Since under these conditions selfpolymerization is aborted in the early stages, the final amount of aggregated protein will tend to be extremely low, thereby drastically reducing infectivity. These concomitant processes greatly limit potential amyloid dissemination from the neuron to the extracellular matrix, and the number of nuclei per neuron. Thus, while amyloid toxicity is responsible for neurological damage, high toxicity levels would reduce the capacity of the amyloid to spread.

\section{AMYLOID RESISTANCE}

High resistance to denaturation could be considered another generic intrinsic characteristic of amyloids and prions. Infectious $\mathrm{PrP}^{\mathrm{Sc}}$ displays the relevant physical, chemical and enzymatic resistance (Sabate, 2014), entailing insufficient cellular clearance, bioavailability, transport and spreading (Aguzzi and Calella, 2009; Soto, 2012; Domert et al., 2014). Since $\mathrm{PrP}^{\mathrm{Sc}}$ cannot easily be degraded by neuronal proteases, the infectious protein persists in the cell, potentiating the seeding capacity and distribution possibilities, and thereby amplifying the infection process.

Importantly, although not yet proven in mammal and human prions, fibril resistance to denaturation could be a key factor in the fragmentation of amyloids. Thus, high resistance has typically been associated with increased fibril rigidity in yeast prions (Tanaka et al., 2004; Castro et al., 2011); this in turn is linked to fragmentation capacity. In this way, more rigid amyloids are not effectively fragmented and generate seeds less efficiently. Since all amyloids appear to show enclosed features, the possibility that a high rate of fibril fragmentation would to be required to favor the spreading of prions would have to be taken into account for all amyloids, including PrP. In summary, the presence of brittle amyloid fibrils increases the number of aggregation nuclei and thereby promotes prion spreading.

\section{AMYLOID LOCATION}

Amyloid location could be a key factor for later spreading. We can envisage two different scenarios: the spreading of extracellular (e.g., $\mathrm{A} \beta$ and $\mathrm{PrP}^{\mathrm{Sc}}$ ) or intracellular (e.g., $\alpha$ syn, $\tau$ or huntingtin protein) amyloids (Sabate, 2014). In the extracellular case, the aggregation process occurs on the extracellular membrane surface, and directly enables both neuron-to-neuron transmission and distal neuronal spreading. In contrast, in intracellular amyloids, the aggregation process 
occurs in the cytosol or nucleus of the neurons, meaning that potential seeds have to be: (1) leaked from an injured neuron to the extracellular matrix; and then (2) internalized from the external matrix into healthy neurons via passive or active mechanisms (i.e., including transference via exocytosis and endocytosis, accumulation into exosomes or micro-vesicles, tunneling nanotubes, tubular membrane bridges interconnecting neurons, and direct synaptic contact; Sherer and Mothes, 2008; Aguzzi and Calella, 2009; Emmanouilidou et al., 2010; Visanji et al., 2013; Narkiewicz et al., 2014). Importantly, whereas neuron-to-neuron transmission could occur via both passive and active mechanisms, distal neuronal spreading is limited to active secretory processes via exocytosis-endocytosis. This suggests that cell death, implying the suppression of active secretion mechanisms, could be extremely unfavorable for spreading; in particular for intracellular amyloids. Although increasing evidence suggests the presence of intracellular amyloids in extracellular biological fluids such as the cerebrospinal fluid, human plasma or saliva (El-Agnaf et al., 2003; Arnoys and Wang, 2007; Devic et al., 2011; Visanji et al., 2013), the concentration of these amyloid-like aggregates in extracellular fluids is very limited. Interestingly, this concentration is expected to be higher in the inter-neuronal space. This would suggest that, although drastically limited, neuron-to-neuron transmission would still be possible, whereas the distal neuronal spreading would be highly improbable.

\section{CONCLUDING REMARKS}

As sketched here, infective capacity could be considered a generic property shared by all amyloids. However, there are several factors that modify the possibility of a non-prion amyloid

\section{REFERENCES}

Aguzzi, A. (2005). Cell biology. Prion toxicity: all sail and no anchor. Science 308, 1420-1421. doi: 10.1126/science.1114168

Aguzzi, A., and Calella, A. M. (2009). Prions: protein aggregation and infectious diseases. Physiol. Rev. 89, 1105-1152. doi: 10.1152/physrev.00006.2009

Aguzzi, A., and Rajendran, L. (2009). The transcellular spread of cytosolic amyloids, prions and prionoids. Neuron 64, 783-790. doi: 10.1016/j.neuron. 2009.12.016

Arnoys, E. J., and Wang, J. L. (2007). Dual localization: proteins in extracellular and intracellular compartments. Acta Histochem. 109, 89-110. doi: 10.1016/j. acthis.2006.10.002

Bahr, B. A., Hoffman, K. B., Yang, A. J., Hess, U. S., Glabe, C. G., and Lynch, G. (1998). Amyloid beta protein is internalized selectively by hippocampal field CA1 and causes neurons to accumulate amyloidogenic carboxyterminal fragments of the amyloid precursor protein. J. Comp. Neurol. 397, 139-147. doi: 10.1002/(sici)1096-9861(19980720)397:1<139::aid-cne10>3.0.co;2-k

Baker, C. A., Martin, D., and Manuelidis, L. (2002). Microglia from CreutzfeldtJakob disease-infected brains are infectious and show specific mRNA activation profiles. J. Virol. 76, 10905-10913. doi: 10.1128/jvi.76.21.1090510913.2002

Banez-Coronel, M., Ayhan, F., Tarabochia, A. D., Zu, T., Perez, B. A., Tusi, S. K., et al. (2015). RAN Translation in Huntington Disease. Neuron 88, 667-677. doi: 10.1016/j.neuron.2015.10.038

Banks, W. A., Robinson, S. M., Diaz-Espinoza, R., Urayama, A., and Soto, C. (2009). Transport of prion protein across the blood-brain barrier. Exp. Neurol. 218, 162-167. doi: 10.1016/j.expneurol.2009.04.025 exhibiting all the properties of a prion. In brief, those factors that favor a high concentration of extracellular nuclei of low toxicity, characterized by a limited size, could dramatically increase prion propensity; whereas, a low concentration of highly toxic large intracellular amyloids would prevent infectivity. Consequently, in humans and mammals, although several amyloid-prone proteins can display certain neuronto-neuron transmission, distal neuronal spreading as well as other potential distribution mechanisms involving not only neurons (e.g., direct crossing of the blood brain barrier or via microglia and immune system cells) required for individual-toindividual infection, have proven to be insufficient to provoke prion activity under natural conditions. Thus, individual-toindividual infection currently seems to remain restricted to PrP.

\section{AUTHOR CONTRIBUTIONS}

$\mathrm{AE}, \mathrm{MAB}$ and JE collaborated in the drafting of the manuscript and RS supervised and drafted the manuscript and edited the draft.

\section{ACKNOWLEDGMENTS}

RS is contracted under the Ramón y Cajal programme (RYC2011-07987), while AE is contracted under the Juan de la Cierva programme (JCI-2012-12193), both financed by the Spanish Ministerio de Economía y Competitividad (MINECO). MAB and JE acknowledge financial support from MINECO to the project MAT2012-36270-C04-03. The authors also acknowledge support through the research groups 2014SGR227 and 2014SGR938 from the Generalitat of Catalunya regional authorities.
Bemporad, F., and Chiti, F. (2012). Protein misfolded oligomers: experimental approaches, mechanism of formation, and structure-toxicity relationships. Chem. Biol. 19, 315-327. doi: 10.1016/j.chembiol.2012.02.003

Bradford, B. M., and Mabbott, N. A. (2012). Prion disease and the innate immune system. Viruses 4, 3389-3419. doi: 10.3390/v4123389

Canevari, L., Abramov, A. Y., and Duchen, M. R. (2004). Toxicity of amyloid beta peptide: tales of calcium, mitochondria and oxidative stress. Neurochem. Res. 29, 637-650. doi: 10.1023/b:nere.0000014834.06405.af

Castro, C. E., Dong, J., Boyce, M. C., Lindquist, S., and Lang, M. J. (2011). Physical properties of polymorphic yeast prion amyloid fibers. Biophys. J. 101, 439-448. doi: 10.1016/j.bpj.2011.06.016

Chesebro, B., Trifilo, M., Race, R., Meade-White, K., Teng, C., LaCasse, R., et al. (2005). Anchorless prion protein results in infectious amyloid disease without clinical scrapie. Science 308, 1435-1439. doi: 10.1126/science. 1110837

Chien, P., Weissman, J. S., and DePace, A. H. (2004). Emerging principles of conformation-based prion inheritance. Annu. Rev. Biochem. 73, 617-656. doi: 10.1146/annurev.biochem.72.121801.161837

Chiti, F., and Dobson, C. M. (2006). Protein misfolding, functional amyloid and human disease. Annu. Rev. Biochem. 75, 333-366. doi: 10.1146/annurev. biochem.75.101304.123901

Clavaguera, F., Bolmont, T., Crowther, R. A., Abramowski, D., Frank, S., Probst, A., et al. (2009). Transmission and spreading of tauopathy in transgenic mouse brain. Nat. Cell Biol. 11, 909-913. doi: 10.1038/ncb1901

Clavaguera, F., Hench, J., Goedert, M., and Tolnay, M. (2015). Invited review: Prion-like transmission and spreading of tau pathology. Neuropathol. Appl. Neurobiol. 41, 47-58. doi: 10.1111/nan.12197 
Cohen, S. I., Linse, S., Luheshi, L. M., Hellstrand, E., White, D. A., Rajah, L., et al. (2013). Proliferation of amyloid-beta 42 aggregates occurs through a secondary nucleation mechanism. Proc. Natl. Acad. Sci. U S A 110, 9758-9763. doi: 10. 1073/pnas.1218402110

Costanzo, M., and Zurzolo, C. (2013). The cell biology of prion-like spread of protein aggregates: mechanisms and implication in neurodegeneration. Biochem. J. 452, 1-17. doi: 10.1042/bj20121898

Desplats, P., Lee, H. J., Bae, E. J., Patrick, C., Rockenstein, E., Crews, L., et al. (2009). Inclusion formation and neuronal cell death through neuron-to-neuron transmission of alpha-synuclein. Proc. Natl. Acad. Sci. U S A 106, 13010-13015. doi: 10.1073/pnas.0903691106

Devic, I., Hwang, H., Edgar, J. S., Izutsu, K., Presland, R., Pan, C., et al. (2011). Salivary alpha-synuclein and DJ-1: potential biomarkers for Parkinson's disease. Brain 134:e178. doi: 10.1093/brain/awr015

Domert, J., Rao, S. B., Agholme, L., Brorsson, A. C., Marcusson, J., Hallbeck, M., et al. (2014). Spreading of amyloid-beta peptides via neuritic cell-to-cell transfer is dependent on insufficient cellular clearance. Neurobiol. Dis. 65, 82-92. doi: 10.1016/j.nbd.2013.12.019

Eisele, Y. S., Obermuller, U., Heilbronner, G., Baumann, F., Kaeser, S. A., Wolburg, H., et al. (2010). Peripherally applied Abeta-containing inoculates induce cerebral beta-amyloidosis. Science 330, 980-982. doi: 10.1126/science. 1194516

El-Agnaf, O. M., Salem, S. A., Paleologou, K. E., Cooper, L. J., Fullwood, N. J., Gibson, M. J., et al. (2003). Alpha-synuclein implicated in Parkinson's disease is present in extracellular biological fluids, including human plasma. FASEB J. 17, 1945-1947. doi: 10.1096/fj.03-0098fje

Emmanouilidou, E., Melachroinou, K., Roumeliotis, T., Garbis, S. D., Ntzouni, M., Margaritis, L. H., et al. (2010). Cell-produced alpha-synuclein is secreted in a calcium-dependent manner by exosomes and impacts neuronal survival. J. Neurosci. 30, 6838-6851. doi: 10.1523/jneurosci.5699-09.2010

Ferrone, F. (1999). Analysis of protein aggregation kinetics. Meth. Enzymol. 309, 256-274. doi: 10.1016/s0076-6879(99)09019-9

Freundt, E. C., Maynard, N., Clancy, E. K., Roy, S., Bousset, L., Sourigues, Y., et al. (2012). Neuron-to-neuron transmission of alpha-synuclein fibrils through axonal transport. Ann. Neurol. 72, 517-524. doi: 10.1002/ana.23747

Frost, B., Jacks, R. L., and Diamond, M. I. (2009). Propagation of tau misfolding from the outside to the inside of a cell. J. Biol. Chem. 284, 12845-12852. doi: 10. 1074/jbc.m808759200

Furukawa, Y., Kaneko, K., Watanabe, S., Yamanaka, K., and Nukina, N. (2011). A seeding reaction recapitulates intracellular formation of Sarkosyl-insoluble transactivation response element (TAR) DNA-binding protein- 43 inclusions. J. Biol. Chem. 286, 18664-18672. doi: 10.1074/jbc.p111.231209

Goedert, M. (2015). Neurodegeneration. Alzheimer's and Parkinson's diseases: The prion concept in relation to assembled Abeta, tau, and a-synuclein. Science 349:1255555. doi: 10.1126/science. 1255555

Goedert, M., Clavaguera, F., and Tolnay, M. (2010). The propagation of prion-like protein inclusions in neurodegenerative diseases. Trends Neurosci. 33, 317-325. doi: $10.1016 /$ j.tins.2010.04.003

Goedert, M., Falcon, B., Clavaguera, F., and Tolnay, M. (2014). Prion-like mechanisms in the pathogenesis of tauopathies and synucleinopathies. Curr. Neurol. Neurosci. Rep. 14: 495. doi: 10.1007/s11910-014-0495-z

Greenwald, J., Buhtz, C., Ritter, C., Kwiatkowski, W., Choe, S., Maddelein, M. L., et al. (2010). The mechanism of prion inhibition by HET-S. Mol. Cell 38, 889-899. doi: 10.1016/j.molcel.2010.05.019

Halliday, M., Radford, H., and Mallucci, G. R. (2014). Prions: generation and spread versus neurotoxicity. J. Biol. Chem. 289, 19862-19868. doi: 10.1074/jbc. R114.568477

Hansen, C., Angot, E., Bergstrom, A. L., Steiner, J. A., Pieri, L., Paul, G., et al. (2011). alpha-Synuclein propagates from mouse brain to grafted dopaminergic neurons and seeds aggregation in cultured human cells. J. Clin. Invest. 121, 715-725. doi: 10.1172/JCI43366

Herva, M. E., and Spillantini, M. G. (2015). Parkinson's disease as a member of Prion-like disorders. Virus Res. 207, 38-46. doi: 10.1016/j.virusres.2014.10.016

Hill, A. F., and Collinge, J. (2003a). Subclinical prion infection. Trends Microbiol. 11, 578-584. doi: 10.1016/j.tim.2003.10.007

Hill, A. F., and Collinge, J. (2003b). Subclinical prion infection in humans and animals. Br. Med. Bull. 66, 161-170. doi: 10.1093/bmb/66.1.161
Hollister, J. R., Lee, K. S., Dorward, D. W., and Baron, G. S. (2015). Efficient uptake and dissemination of scrapie prion protein by astrocytes and fibroblasts from adult hamster brain. PLoS One 10:e0115351. doi: 10.1371/journal.pone.0115351

Holmes, B. B., and Diamond, M. I. (2014). Prion-like properties of Tau protein: the importance of extracellular Tau as a therapeutic target. J. Biol. Chem. 289, 19855-19861. doi: 10.1074/jbc.r114.549295

Hyman, B. T. (2014). Tau propagation, different tau phenotypes and prion-like properties of tau. Neuron. 82, 1189-1190. doi: 10.1016/j.neuron.2014.06.004

Isaacs, J. D., Jackson, G. S., and Altmann, D. M. (2006). The role of the cellular prion protein in the immune system. Clin. Exp. Immunol. 146, 1-8. doi: 10. 1111/j.1365-2249.2006.03194.x

Jarrett, J. T., and Lansbury, P. T. (1993). Seeding "one-dimensional crystallization" of amyloid: a pathogenic mechanism in Alzheimer's disease and scrapie? Cell 73, 1055-1058.

Jucker, M., and Walker, L. C. (2011). Pathogenic protein seeding in Alzheimer disease and other neurodegenerative disorders. Ann. Neurol. 70, 532-540. doi: 10.1002/ana.22615

Kane, M. D., Lipinski, W. J., Callahan, M. J., Bian, F., Durham, R. A., Schwarz, R. D., et al. (2000). Evidence for seeding of beta -amyloid by intracerebral infusion of Alzheimer brain extracts in beta -amyloid precursor proteintransgenic mice. J. Neurosci. 20, 3606-3611.

Kaufman, S. K., and Diamond, M. I. (2013). Prion-like propagation of protein aggregation and related therapeutic strategies. Neurotherapeutics 10, 371-382. doi: 10.1007/s13311-013-0196-3

Knowles, T. P., Waudby, C. A., Devlin, G. L., Cohen, S. I., Aguzzi, A., Vendruscolo, M., et al. (2009). An analytical solution to the kinetics of breakable filament assembly. Science 326, 1533-1537. doi: 10.1126/science.1178250

Lashuel, H. A., Hartley, D., Petre, B. M., Walz, T., and Lansbury, P. T. (2002). Neurodegenerative disease: amyloid pores from pathogenic mutations. Nature 418:291. doi: 10.3410/f.1007996.100655

Lashuel, H. A., and Lansbury, P. T. (2006). Are amyloid diseases caused by protein aggregates that mimic bacterial pore-forming toxins? Q. Rev. Biophys. 39, 167-201. doi: 10.1017/S0033583506004422

Lomakin, A., Chung, D. S., Benedek, G. B., Kirschner, D. A., and Teplow, D. B. (1996). On the nucleation and growth of amyloid beta-protein fibrils: detection of nuclei and quantitation of rate constants. Proc. Natl. Acad. Sci. U S A 93, 1125-1129. doi: 10.1073/pnas.93.3.1125

Lomakin, A., Teplow, D. B., Kirschner, D. A., and Benedek, G. B. (1997). Kinetic theory of fibrillogenesis of amyloid beta-protein. Proc. Natl. Acad. Sci. U S A 94, 7942-7947. doi: 10.1073/pnas.94.15.7942

Luk, K. C., Kehm, V. M., Zhang, B., O’Brien, P., Trojanowski, J. Q., and Lee, V. M. (2012). Intracerebral inoculation of pathological alpha-synuclein initiates a rapidly progressive neurodegenerative alpha-synucleinopathy in mice. J. Exp. Med. 209, 975-986. doi: 10.1084/jem.20112457

Maddelein, M. L., Dos Reis, S., Duvezin-Caubet, S., Coulary-Salin, B., and Saupe, S. J. (2002). Amyloid aggregates of the HET-s prion protein are infectious. Proc. Natl. Acad. Sci. U S A 99, 7402-7407. doi: 10.1073/pnas.072199199

Malato, L., Dos Reis, S., Benkemoun, L., Sabaté, R., and Saupe, S. J. (2007). Role of Hsp104 in the propagation and inheritance of the [Het-s] prion. Mol. Biol. Cell 18, 4803-4812. doi: 10.1091/mbc.e07-07-0657

Mallucci, G., Dickinson, A., Linehan, J., Klöhn, P. C., Brandner, S., and Collinge, J. (2003). Depleting neuronal PrP in prion infection prevents disease and reverses spongiosis. Science 302, 871-874. doi: 10.1126/science.1090187

Marella, M., and Chabry, J. (2004). Neurons and astrocytes respond to prion infection by inducing microglia recruitment. J. Neurosci. 24, 620-627. doi: 10. 1523/JNEUROSCI.4303-03.2004

Masuda-Suzukake, M., Nonaka, T., Hosokawa, M., Oikawa, T., Arai, T., Akiyama, H., et al. (2013). Prion-like spreading of pathological alpha-synuclein in brain. Brain 136, 1128-1138. doi: 10.1093/brain/awt037

Mathur, V., Seuring, C., Riek, R., Saupe, S. J., and Liebman, S. W. (2012). Localization of HET-S to the cell periphery, not to [Het-s] aggregates, is associated with [Het-s]-HET-S toxicity. Mol. Cell Biol. 32, 139-153. doi: 10. 1128/MCB.06125-11

Meisl, G., Yang, X., Hellstrand, E., Frohm, B., Kirkegaard, J. B., Cohen, S. I., et al. (2014). Differences in nucleation behavior underlie the contrasting aggregation kinetics of the Abeta40 and Abeta42 peptides. Proc. Natl. Acad. Sci. U S A 111, 9384-9389. doi: 10.1073/pnas.1401564111 
Meyer-Luehmann, M., Coomaraswamy, J., Bolmont, T., Kaeser, S., Schaefer, C., Kilger, E., et al. (2006). Exogenous induction of cerebral beta-amyloidogenesis is governed by agent and host. Science 313, 1781-1784. doi: 10.1126/science. 1131864

Morris, A. M., Watzky, M. A., Agar, J. N., and Finke, R. G. (2008). Fitting neurological protein aggregation kinetic data via a 2-step, minimal/“Ockham's razor" model: the Finke-Watzky mechanism of nucleation followed by autocatalytic surface growth. Biochemistry 47, 2413-2427. doi: 10 . 1021/bi701899y

Mougenot, A. L., Nicot, S., Bencsik, A., Morignat, E., Verchère, J., Lakhdar, L., et al. (2012). Prion-like acceleration of a synucleinopathy in a transgenic mouse model. Neurobiol. Aging 33, 2225-2228. doi: 10.1016/j.neurobiolaging.2011. 06.022

Münch, C., O’Brien, J., and Bertolotti, A. (2011). Prion-like propagation of mutant superoxide dismutase-1 misfolding in neuronal cells. Proc. Natl. Acad. Sci. U S A 108, 3548-3553. doi: 10.1073/pnas.1017275108

Narkiewicz, J., Giachin, G., and Legname, G. (2014). In vitro aggregation assays for the characterization of alpha-synuclein prion-like properties. Prion 8, 19-32. doi: $10.4161 /$ pri.28125

Nath, S., Agholme, L., Kurudenkandy, F. R., Granseth, B., Marcusson, J., and Hallbeck, M. (2012). Spreading of neurodegenerative pathology via neuronto-neuron transmission of beta-amyloid. J. Neurosci. 32, 8767-8777. doi: 10 . 1523/JNEUROSCI.0615-12.2012

Ono, K., Condron, M. M., and Teplow, D. B. (2009). Structure-neurotoxicity relationships of amyloid beta-protein oligomers. Proc. Natl. Acad. Sci. U S A 106, 14745-14750. doi: 10.1073/pnas.0905127106

Pearce, M. M., Spartz, E. J., Hong, W., Luo, L., and Kopito, R. R. (2015). Prionlike transmission of neuronal huntingtin aggregates to phagocytic glia in the Drosophila brain. Nat. Commun. 6:6768. doi: 10.1038/ncomms7768

Petkova, A. T., Leapman, R. D., Guo, Z., Yau, W. M., Mattson, M. P., and Tycko, R. (2005). Self-propagating, molecular-level polymorphism in Alzheimer's betaamyloid fibrils. Science 307, 262-265. doi: 10.1126/science.1105850

Polanco, J. C., and Götz, J. (2015). No full admission for tau to the exclusive prion club yet. EMBO J. 34, 2990-2992. doi: 10.15252/embj.201593311

Polymenidou, M., and Cleveland, D. W. (2011). The seeds of neurodegeneration: prion-like spreading in ALS. Cell 147, 498-508. doi: 10.1016/j.cell.2011. 10.011

Polymenidou, M., and Cleveland, D. W. (2012). Prion-like spread of protein aggregates in neurodegeneration. J. Exp. Med. 209, 889-893. doi: 10.1084/jem. 20120741

Prangkio, P., Yusko, E. C., Sept, D., Yang, J., and Mayer, M. (2012). Multivariate analyses of amyloid-beta oligomer populations indicate a connection between pore formation and cytotoxicity. PLoS One 7:e47261. doi: 10.1371/journal. pone. 0047261

Race, B., Phillips, K., Meade-White, K., Striebel, J., and Chesebro, B. (2015). Increased infectivity of anchorless mouse scrapie prions in transgenic mice overexpressing human prion protein. J. Virol. 89, 6022-6032. doi: 10.1128/JVI. 00362-15

Ren, P. H., Lauckner, J. E., Kachirskaia, I., Heuser, J. E., Melki, R., and Kopito, R. R. (2009). Cytoplasmic penetration and persistent infection of mammalian cells by polyglutamine aggregates. Nat. Cell Biol. 11, 219-225. doi: 10.1038/ ncb 1830

Reyes, J. F., Rey, N. L., Bousset, L., Melki, R., Brundin, P., and Angot, E. (2014). Alpha-synuclein transfers from neurons to oligodendrocytes. Glia 62, 387-398. doi: $10.1002 /$ glia.22611

Sabate, R. (2014). When amyloids become prions. Prion 8, 233-239. doi: 10. $4161 / 19336896.2014 .968464$

Sakono, M., and Zako, T. (2010). Amyloid oligomers: formation and toxicity of Abeta oligomers. FEBS J. 277, 1348-1358. doi: 10.1111/j.1742-4658.2010. 07568.x

Sandberg, M. K., Al-Doujaily, H., Sharps, B., Clarke, A. R., and Collinge, J. (2011). Prion propagation and toxicity in vivo occur in two distinct mechanistic phases. Nature 470, 540-542. doi: 10.1038/nature09768
Serio, T. R., Cashikar, A. G., Kowal, A. S., Sawicki, G. J., Moslehi, J. J., Serpell, L., et al. (2000). Nucleated conformational conversion and the replication of conformational information by a prion determinant. Science 289, 1317-1321. doi: $10.1126 /$ science.289.5483.1317

Seuring, C., Greenwald, J., Wasmer, C., Wepf, R., Saupe, S. J., Meier, B. H., et al. (2012). The Mechanism of Toxicity in HET-S/HET-s Prion Incompatibility. PLoS Biol. 10:e1001451. doi: 10.1371/journal.pbio.1001451

Sherer, N. M., and Mothes, W. (2008). Cytonemes and tunneling nanotubules in cell-cell communication and viral pathogenesis. Trends Cell Biol. 18, 414-420. doi: $10.1016 /$ j.tcb.2008.07.003

Silveira, J. R., Raymond, G. J., Hughson, A. G., Race, R. E., Sim, V. L., Hayes, S. F., et al. (2005). The most infectious prion protein particles. Nature 437, 257-261. doi: 10.1038 /nature03989

Simoneau, S., Rezaei, H., Salès, N., Kaiser-Schulz, G., Lefebvre-Roque, M., Vidal, C., et al. (2007). in vivo and in vivo neurotoxicity of prion protein oligomers. PLoS Pathog. 3:e125. doi: 10.1371/journal.ppat.0030125

Soto, C. (2012). Transmissible proteins: expanding the prion heresy. Cell 149, 968-977. doi: 10.1016/j.cell.2012.05.007

Spillantini, M. G., and Goedert, M. (2013). Tau pathology and neurodegeneration. Lancet Neurol. 12, 609-622. doi: 10.1016/S1474-4422(13)70090-5

Stöhr, J., Watts, J. C., Mensinger, Z. L., Oehler, A., Grillo, S. K., DeArmond, S. J., et al. (2012). Purified and synthetic Alzheimer's amyloid beta (Abeta) prions Proc. Natl. Acad. Sci. U S A 109, 11025-11030. doi: 10.1073/pnas.1206555109

Tanaka, M., Chien, P., Naber, N., Cooke, R., and Weissman, J. S. (2004). Conformational variations in an infectious protein determine prion strain differences. Nature 428, 323-328. doi: 10.1038/nature02392

Tanaka, M., Collins, S. R., Toyama, B. H., and Weissman, J. S. (2006). The physical basis of how prion conformations determine strain phenotypes. Nature 442, 585-589. doi: 10.1038/nature04922

Trevino, R. S., Lauckner, J. E., Sourigues, Y., Pearce, M. M., Bousset, L., Melki, R., et al. (2012). Fibrillar structure and charge determine the interaction of polyglutamine protein aggregates with the cell surface. J. Biol. Chem. 287, 29722-29728. doi: 10.1074/jbc.M112.372474

Tu, J., Chen, B., Yang, L., Qi, K., Lu, J., and Zhao, D. (2015). Amyloid-beta Activates Microglia and Regulates Protein Expression in a Manner Similar to Prions. J. Mol. Neurosci. 56, 509-518. doi: 10.1007/s12031-015-0553-2

Uptain, S. M., and Lindquist, S. (2002). Prions as protein-based genetic elements. Annu. Rev. Microbiol. 56, 703-741. doi: 10.1146/annurev.micro.56.013002. 100603

Visanji, N. P., Brooks, P. L., Hazrati, L. N., and Lang, A. E. (2013). The prion hypothesis in Parkinson's disease: Braak to the future. Acta Neuropathol. Commun. 1:2. doi: 10.1186/2051-5960-1-2

Walker, L. C., Diamond, M. I., Duff, K. E., and Hyman, B. T. (2013). Mechanisms of protein seeding in neurodegenerative diseases. JAMA Neurol. 70, 304-310. doi: 10.1001/jamaneurol.2013.1453

Walker, L. C., Levine, H. 3rd, Mattson, M. P., and Jucker, M. (2006). Inducible proteopathies. Trends Neurosci. 29, 438-443. doi: 10.1016/j.tins.2006.06.010

Conflict of Interest Statement: The authors declare that the research was conducted in the absence of any commercial or financial relationships that could be construed as a potential conflict of interest.

The reviewer NS and handling Editor declared their shared affiliation, and the handling Editor states that the process nevertheless met the standards of a fair and objective review.

Copyright () 2016 Espargaró, Busquets, Estelrich and Sabate. This is an open-access article distributed under the terms of the Creative Commons Attribution License (CC BY). The use, distribution and reproduction in other forums is permitted, provided the original author(s) or licensor are credited and that the original publication in this journal is cited, in accordance with accepted academic practice. No use, distribution or reproduction is permitted which does not comply with these terms. 